\title{
The Conflict and Balance between Government's Information Right and Citizen’s Privacy Right
}

\author{
Hong Li \\ School of Law, Changchun University of Science and Technology \\ Weixing Road 7989, Changchun, China
}

Received: June 20, 2011

Accepted: July 6, 2011

doi:10.5539/jpl.v4n2p104

\begin{abstract}
Along with the development of society informatization, government is required to possess information right to make policy and offer better service. However, performing the information right will inevitably influence citizen's privacy right. How to balance the relationship between government's information right and citizen's privacy right when the two are in conflict? According to modern administrative balance theory, on the one hand, administrative right should be restricted which means the performance of information right should be done in accordance with the principle of legality and non-abuse. On the other hand, the citizen's privacy right should be restricted, namely defining the exception cases of privacy right.
\end{abstract}

Keywords: Government information right, Citizen’s privacy right, Conflicts, Balance

Rule of Government Information Publicity has been put into force, which symbolizes the beginning of citizen's right to know and the establishment of legal protection system. Along with citizen's right to know and the expanding government information need, an important legal issue should draw people's concern. Privacy right, as a kind of civil right, is attracting more and more concern from people and is protected by countries' law, due to its close relationship with citizen's personal life. However, as administrative right is permeating into personal field, a certain amount of personal information is known by administrative organizations and becomes a part of government information. Citizen's privacy may bear threat from other civil subjects and on the other hand may be infringed by governmental organization when it performs information right. As a consequence, the relationship between the two should be carefully balanced.

1. Government information refers to information that authorities gain, use, spread, save and in charge when they perform their function. In the composition of society informatization, government is the main information collector, consumer and announcer. From the angel of information production and application, government information right means government's right to gain, announce and deal with all necessary data and information through legal procedure and method.(Zhou, 2003, p.57)). The legality of government information bases on making correct decisions. Only when government is capable to gain, announce and deal with necessary data and information, can it perform its administrative function. Since the society in highly informationized, administrative efficiency depends at large on quick and accurate information resource. Strengthening public information can effectively centralize the information for government to manage public affairs. Therefore, the government can judge the social's development in time and in accuracy, and accomplish developing goals and missions.

Scholars have different opinions on the displaying forms of government information right. Professor Bernard Schwartz holds that the administrative authorities can perform the following rights: first, the right to make record and file; second, the right to check account book and file; third, the right to subpoena witness and demand file. (Yu, 2009) Professor Wang Ming, however, considers that the administrative authorities' information rights displayed as follows. First, ask the investigated man to provide documents or files in specified form, or provide the report right. Second, investigate on the buildings, documents and files. Third, issue summons and ask the investigated man to testify or provide account book, documents and files. (Wang, 1995 p.103). As far as myself is concerned, government information right mainly displays in the following forms.

First, it is the right to gain information. In another word, it means the right to collect necessary information by lawful ways. It is the most basic government information right. If the right to gain information cannot be guaranteed, other government information cannot be realized. Its role as public managed cannot be performed.

Second, it is the right to announce information. It refers the right to announce economic and social information through public ways. By announcing such information, social information resources can be effectively integrated. It 
can also help people to distinguish true information from false one and level the information's efficiency of usage.

Third, it is the right to deal with information. Namely, save, process and analyze all kinds of data and information to meet government's needs. When process information, authorities use the information but also produce information. By saving, processing and analyzing information, informative management and decisions can be made. Thus, the government's service level can be increased.

2. Modern information society is greatly changing government's role, making it much more efficient and its decisions more accurate. For fulfilling this function, the government has to rely on more information resource and government information rights may enter into more fields. When it enters into personal field, it will inevitably involve in citizen's private information, which may lead tension to the two's relationship. Essentially, there is no difference between collecting, processing and dealing with citizen's personal information and managing public affairs. There is no doubt that government needs a great quantity of personal information to provide people with better service, manage the nation's public affairs and seek for improvement. Meanwhile, modern society requires that government should public the information, transparentize the administration and let citizens know what the government has done and supervise it. However, privacy right is a right of personality, which means that other people have the obligation not to violate one's privacy right. Namely, the law entrust citizen with right to control spreading information about him or herself. A citizen has the right to disclose or not his or her privacy and to what extent the privacy can be disclosed. Disclosing one's private information without permission and abusing in using one's privacy information are violations to citizen's privacy right. Therefore, there appear conflicts between government's usage of personal information and individual's protection of privacy. How to balance the two's relationship is an important legal issue that needs people's careful reflection.

In practice, the first conflict between government information right and individual privacy right is that the two cannot reach agreement on whether certain personal information belongs to the category of privacy information. Secondly, there is a dispute on whether the information announced by government has allowed by the citizens and whether the information has exceeded the degree that citizens have allowed. Lastly, whether the information announced by government are that can be obtained by government.

The essence of modern administrative law is to limit government' right and to guarantee citizen's right. Administrative right and civil right constitute the theme of modern administration. Originally, traditional administrative theory holds that civil right is the basis of administrative right which originates from civil right. However, in the angle of real status they are in conflict with each other. Firstly, administrative right and civil right repel each other. The expansivity of right makes all man who is entrusted with right abuse in using right. Therefore, people are always cautious of administrative right and try to negotiate it. Correspondingly, administrative right and civil right have different interests. Administrative right points to public interest while citizen right points to individual interest. They belong to different fields. Actually, as long as there is society, the conflicts between administrative right and civil right cannot be avoided. Therefore, we should try to find a balance between administrative right and civil right instead of eliminating the conflicts. As some scholars point out, a better administrative pattern should define a reasonable boundary between the two and establish a mutual coordination pattern so as to guarantee the proper performance of administrative right and limit reasonably on civil right to better protect civil right.

Since the conflicts between administrative right v.s. civil right and public interest vs. individual interest are inevitable phenomenon of modern society. The proper way to deal with the conflicts should take all factors into consideration and should not focus on one part's interest. According to the balance theory of administrative law, the purpose of administrative law should be a balance between administrative right and civil right and public interest and individual interest. As for the relationship of administration subject and object, their right and obligation should be equal. On the one hand, it is necessary to entrust the administration with certain right to control and supervise the public order and on the other hand, it is of great importance to control and supervise the administrative right to protect citizens' legal right. The final result should be the maximization of all parties' interest. (Luo, 1997, p.37)) The balance theory is a kind of unity of opposites. Namely, either part should be ignored or eliminated by the other part. Dworkin once points in his right theory that the key to deal with relationship between individual interest and public interest is the compromise of each party.

3. According to the mentioned theory, when government information right is in confliction with individual privacy right the solutions can be:

\subsection{The performance of government information right should obey the principle of legality and should not be abused}

Principle of legality refers to the administrative subject must strictly obey administrative laws and regulations and should not violate laws when performing administrative right. As far as the performance of government information 
right, principle of legality requires that national administration must be endowed with certain legal right when performing information right and it should be done within the scope of its duty. Administrative authorities that have not be entrusted with corresponding duties do not have right to produce, collect, save, spread and deal with any information. Meanwhile, principle of legality also requires that the authorities should obey lawful procedures when performing its information right to avoid the abuse of right.

However, in modern society, government is taking overall intervention of society and economy and government's function to manage social and economic affairs is increasingly expanding. Hence, modern administration is becoming more diverse and complicated. As a consequence, it is impossible to make detailed specifications and rules to control administrative performance by law. The administrative authorities are therefore given moderate discretionary power to accommodate the complicated and changing society. Hence, there appears discretionary power. When government is performing information right, the judgment of information scope, determination of object and the necessity of collecting information are all infused with discretionary power. As a consequence, principle of non-abuse should be taken to control government information right.

Principle of non-abuse includes necessity and proportion. The former requires that authorities should take the way that affects the respondent the most slightly when choosing several potential methods to achieve the same object. While the latter means that the intervention for respondent's right should not exceed the value of administration object. As far as government information right is concerned, non-abuse principle requires that authorities should consider the cost and benefit of collecting, saving and announcing information for government and citizens. Specifically, it should obey the following request.

3.1.1 When collecting information, individual agreement must be obtained to announce and use the information unless specified by laws or public interests. If the government collects information from a third-party or existing information from other authorities, it should check with the respondent and ensure the accuracy of that information.

3.1.2 When saving personal information, especially editing and reconstructing personal information, particular attention must be give to its accuracy. If the saved information has inaccurate information, it will bring unfavorable results to citizens when public the administrative information. At the same time, administrative authority is obliged to guarantee the safety of the saved information.

3.1.3 When making the personal information public, the authority should restrict the spread of personal information. Authorities are forbidden to provide such information to other organization or individual with the purpose of business.

\subsection{Specify the exception of citizen's privacy right by law}

As a kind of civil right protected by law, citizen's privacy right is not absolutely free. Civil right is entrusted with social obligation. Article 51 of the Constitution of the People's Republic of China rules that when performing the right and freedom entrusted by Constitution, citizens should not violate the interests of nation, society, organization and other citizens' lawful right and interest. This is the basis of limitation on privacy right which includes the following three aspects.

3.2.1 Agreement of citizen. As for personal information, activity and domain which has nothing to do with public interest, the authorities have no right to collect such information or make it public without citizen's agreement.

3.2.2 Rules of law and regulation. If there are specific laws ruling that authorities have the right to acquire related personal resources, to sanction crime and prevent unlawful act, the respondent is obliged to offer the information.

3.2.3 Necessity of public interest. In principle, personal privacy right is protected by law, but when such privacy is involved in public interest, things will be different. Modern administrative theory holds that public interest is the legal reason to limit citizen's right. The performance of civil right should not go against public interest and at the same time it is obliged to enhance public interest. When involved in public interest, personal right should yield for more people's interest. Engels once points that when privacy is involved in public interest, privacy becomes a part of politics.

In a word, in modern information society, the performance of government information right and the protection of citizen's privacy right are two developing trends. It is believed that with the establishment of a service government and the increase of citizen's right consciousness, the conflicts between the two parties will be balanced by designing a law system.

\section{References}

Haocai Luo. (1997). Balance Theory of Modern Administrative Law. Peking University Press.

Lishen Yu.(2009). On Government's Information Right and Respondent's Obligation. Law and Social Development. 
Min Lin. (2007).Conflicts and Coordination between Right to Know and Privacy Right of Information Announced by Government. Library and Information Service.

Mingyang Wang. (1995). Administrative Law of The United States. China Legal Publishing House.

Qingshan Zhou. (2003). Law of Information. China Renmin University Press.

Shumei Xia \& Xiancun Ding. (2004). Exploration on the Privacy Right of the Information Announced by Government. Chinese Public Administration. 